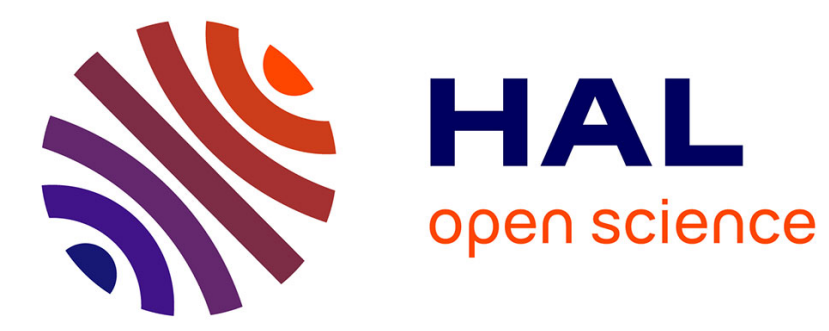

\title{
Crystal Structure of Mouse Acetylcholinesterase
}

Yves Bourne, Palmer Taylor, Pierre E Bougis, P. Marchot

\section{To cite this version:}

Yves Bourne, Palmer Taylor, Pierre E Bougis, P. Marchot. Crystal Structure of Mouse Acetylcholinesterase: A PERIPHERAL SITE-OCCLUDING LOOP IN A TETRAMERIC ASSEMBLY. Journal of Biological Chemistry, 1999, 274 (5), pp.2963-2970. 10.1074/jbc.274.5.2963 . hal-03262510

\section{HAL Id: hal-03262510 https://hal-amu.archives-ouvertes.fr/hal-03262510}

Submitted on 16 Jun 2021

HAL is a multi-disciplinary open access archive for the deposit and dissemination of scientific research documents, whether they are published or not. The documents may come from teaching and research institutions in France or abroad, or from public or private research centers.
L'archive ouverte pluridisciplinaire HAL, est destinée au dépôt et à la diffusion de documents scientifiques de niveau recherche, publiés ou non, émanant des établissements d'enseignement et de recherche français ou étrangers, des laboratoires publics ou privés.

\section{(c)(1)}

Distributed under a Creative Commons Attribution| 4.0 International License 


\title{
Crystal Structure of Mouse Acetylcholinesterase
}

\author{
A PERIPHERAL SITE-OCCLUDING LOOP IN A TETRAMERIC ASSEMBLY*
}

(Received for publication, August 21, 1998, and in revised form, October 28, 1998)

\begin{abstract}
Yves Bourneł, Palmer Taylor§, Pierre E. Bougisף, and Pascale Marchotin|
From $\ddagger C N R S$, Unité Propre de Recherche 9039, Architecture et Fonction des Macromolécules Biologiques, Institut de Biologie et Microbiologie Structurale, F-13402 Marseille Cedex 20, France, the §Department of Pharmacology, University of California at San Diego, La Jolla, California 92093-0636, and $₫$ CNRS, Unité Mixte de Recherche 6560, Ingénierie des Protéines, Institut Fédératif de Recherche Jean Roche, Université de la Méditerranée, Faculté de Médecine Secteur Nord, F-13916 Marseille Cedex 20, France
\end{abstract}

\begin{abstract}
The crystal structure of mouse acetylcholinesterase at 2.9-Å resolution reveals a tetrameric assembly of subunits with an antiparallel alignment of two canonical homodimers assembled through four-helix bundles. In the tetramer, a short $\Omega$ loop, composed of a cluster of hydrophobic residues conserved in mammalian acetylcholinesterases along with flanking $\alpha$-helices, associates with the peripheral anionic site of the facing subunit and sterically occludes the entrance of the gorge leading to the active center. The inverse loop-peripheral site interaction occurs within the second pair of subunits, but the peripheral sites on the two loop-donor subunits remain freely accessible to the solvent. The position and complementarity of the peripheral site-occluding loop mimic the characteristics of the central loop of the peptidic inhibitor fasciculin bound to mouse acetylcholinesterase. Tetrameric forms of cholinesterases are widely distributed in nature and predominate in mammalian brain. This structure reveals a likely mode of subunit arrangement and suggests that the peripheral site, located near the rim of the gorge, is a site for association of neighboring subunits or heterologous proteins with interactive surface loops.
\end{abstract}

Acetylcholinesterase (AChE), ${ }^{1}$ a member of the family of proteins with an $\alpha / \beta$-hydrolase fold $(1,2)$, rapidly terminates cholinergic neurotransmission by hydrolysis of acetylcholine ( 3 , 4). In mammals, AChE is encoded by a single gene, yet a multiplicity of molecular forms arise through alternative

* This work was supported by United States Public Health Service Grant GM18360 and Department of Army Medical Defense Grant 171-8014 (to P. T.); National Science Foundation-CNRS Collaborative Project 3906 (to P. M. and P. T.); the Association Française contre les Myopathies (to P. E.B. and P. M.); and the European Union (HCMP Access to Large Installations Project, Contract CHGE-CT93-0040) and CNRS (to Y. B. and P. M. for data collection at EMBL Hamburg and the Laboratoire pour l'Utilisation du Rayonnement Electromagnétic, respectively). Part of this work was presented during the Sixth International Meeting on Cholinesterases and Related Proteins, La Jolla, CA, 1998). The costs of publication of this article were defrayed in part by the payment of page charges. This article must therefore be hereby marked "advertisement" in accordance with 18 U.S.C. Section 1734 solely to indicate this fact.

The atomic coordinates of structure A (code 1MAA) have been deposited in the Protein Data Bank, Brookhaven National Laboratory, Upton, NY.

|| To whom correspondence should be addressed. Fax: 33-4-9165-7595. E-mail: marchot.p@jean-roche.univ-mrs.fr.

${ }^{1}$ The abbreviations used are: AChE, acetylcholinesterase; $\mathrm{mAChE}$, recombinant mouse AChE; TcAChE, T. californica AChE; Fas2, fasciculin 2; DECA, decamethonium; EDR, edrophonium (ethyl-3-hydroxyphenyl dimethylammonium); MES, 2-( $N$-morpholino)ethanesulfonic acid; NCS, non-crystallographic symmetry; r.m.s., root mean square.
mRNA processing and association of the catalytic subunits with structural subunits. Alternative mRNA processing gives rise to three splicing options: $(a)$ a soluble monomer without the capacity for disulfide linkage; (b) a glycophospholipid-linked form that is membrane-associated and exists as monomers and dimers; and (c) an amphiphilic form found as monomers, dimers and tetramers (in the tetramer, amphiphilic character may be lost presumably through occlusion of the hydrophobic surfaces). Further structural complexity is achieved in the tetrameric assemblies through disulfide association of the catalytic subunits with structural subunits that are either amphipathic or collagen-like, giving rise to predominant forms in brain and skeletal muscle. The tetrameric forms are dimers of dimers where one set of disulfides links with a polyprolinecontaining structural subunit (5) and the other set is formed between monomers $(3,4)$. However, there is currently little structural information about the subunit orientation in the tetramer and the association of tetramers with structural subunits.

Differences in the molecular forms of the cholinesterases are the primary determinants of their cellular disposition (3). Abnormal associations of AChE are apparent in Alzheimer's dementia, where a selective loss of the amphiphilic tetramers is observed $(6,7)$. AChE was suggested to associate with or to nucleate the neuritic plaques found in the disease (8-12); however, the mode of this association is unknown.

The active center of $\mathrm{AChE}$, which consists of the triad $\mathrm{Ser}^{203}$ $\mathrm{Glu}^{334}-\mathrm{His}^{447}$ in mammals (13), is nearly centrosymmetric to the subunit and is located at the bottom of a narrow gorge (14). Inhibitors may bind at the active center or at a distant allosteric site, the peripheral anionic site, located at the gorge rim. The structure of recombinant monomeric mouse AChE (mA$\mathrm{ChE}$ ) in a complex with the peptidic inhibitor fasciculin 2 (Fas2), bound to the peripheral anionic site, provided the first mammalian cholinesterase template (15). Only slight differences were observed in the conformation of Fas2-associated mAChE compared with uncomplexed Torpedo californica AChE (TcAChE) (14). However, it was not possible to distinguish species-related differences from changes in conformation accompanying Fas2 binding. Indeed, little difference in TcAChE conformation was observed between structures of the apoenzyme (14) and the Fas2 complex (16). In addition, currently available crystal structures of $\mathrm{AChE}$ reveal the entrance of the active site gorge to be either occluded by a symmetryrelated molecule $(14,17,18)$ or sealed with high surface complementarity by Fas2 $(15,16)$, therefore precluding structural analysis of an unprotected peripheral anionic site region.

The crystal structure of $\mathrm{mAChE}$ refined to $2.9-\AA$ resolution has good stereochemistry, with an $R$-factor of $21.5 \%$ for data in the 15 to $2.9-\AA$ resolution range, and contains four $\mathrm{mAChE}$ 
TABLE I

Data collection and refinement statistics

\begin{tabular}{|c|c|c|c|}
\hline & Structure A & Structure B & Structure C \\
\hline \multicolumn{4}{|l|}{ Data collection } \\
\hline Synchrotron source & DESY & DESY & LURE \\
\hline Beam line & $\mathrm{X} 11$ & BW7B & DW32 \\
\hline Resolution range $(\AA)$ & 15 to 2.9 & 15 to 3.1 & 15 to 3.1 \\
\hline Total observations & 604,052 & 727,622 & 636,975 \\
\hline Unique reflections & 107,379 & 99,326 & 92,186 \\
\hline Multiplicity & 2.8 & 2.6 & 3.3 \\
\hline \multicolumn{4}{|l|}{ Completeness $(\%)$} \\
\hline Overall (final shell) & $92(90)$ & $90(78)$ & $96(92)$ \\
\hline$R_{\text {merge }}(\text { final shell })^{a}$ & $10.5(37)$ & $12(39)$ & $13(42)$ \\
\hline \multicolumn{4}{|l|}{ Refinement } \\
\hline$R$-factor $(\%)^{b}$ & 21.5 & 23.0 & 23.0 \\
\hline$R_{\text {free }}(\%)^{c}$ & 24.5 & 26.0 & 26.0 \\
\hline \multicolumn{4}{|l|}{ r.m.s. deviation ${ }^{d}$} \\
\hline Bonds $(\AA)$ & 0.011 & 0.011 & 0.011 \\
\hline Angles $\left({ }^{\circ}\right)$ & 1.6 & 1.6 & 1.6 \\
\hline \multicolumn{4}{|l|}{ Average $B$-factor $(\AA)^{b}$} \\
\hline Main chains & 40.6 & 42.3 & 43.2 \\
\hline Side chains & 45.3 & 46.2 & 48.1 \\
\hline Solvent & 42 & $\mathrm{ND}^{e}$ & ND \\
\hline Decamethonium/edrophonium & 68 & 27 & ND \\
\hline Oligosaccharide & 75 & 78 & 74 \\
\hline \multicolumn{4}{|l|}{ Ramachandran plot } \\
\hline Residues in most favored regions (\%) & 84 & 84 & 84 \\
\hline Residues in additionally allowed regions (\%) & 15.5 & 15.5 & 15.5 \\
\hline
\end{tabular}

${ }^{a} R_{\text {merge }}=\sum|I-\langle I\rangle| / \sum I$, where $I$ is an individual reflection measurement and $\langle I\rangle$ is the mean intensity for symmetry-related reflections.

${ }^{b} R$-factor $=\Sigma|| \mathrm{F}_{o}|-| F_{c}|| / \Sigma\left|F_{o}\right|$, where $F_{o}$ and $F_{c}$ are observed and calculated structure factors, respectively.

${ }^{c} R_{\text {free }}$ is calculated for $2 \%$ of randomly selected reflections excluded from refinement.

${ }^{d}$ r.m.s. deviation from ideal values.

${ }^{e} \mathrm{ND}$, not determined.

monomers assembled as a tetramer, three GlcNAc moieties and one GlcNAc- $\beta 1,4-G l c N A c-\alpha 1,6$-Fuc trisaccharide moiety linked to Asn residues, four decamethonium (DECA) molecules, four phosphate groups, four glycerol molecules, and 205 water molecules in the asymmetric unit. The structure of $\mathrm{mAChE}$ provides significantly improved accuracy in the positions of the main and side chains of the molecule over the Fas2 2 mAChE structure, reveals distinctive features of the mouse enzyme, and permits direct comparison of solvent-exposed and -occluded peripheral anionic sites within the same crystal unit. More importantly, this structure highlights surface determinants that could participate in formation of oligomers upon assembly in normal and pathological states, in allosteric modulation of catalysis, and in forming heterologous cell contacts.

\section{EXPERIMENTAL PROCEDURES}

Purification, Crystallization, and Data Collection-Soluble mAChE expressed in HEK-293 cells was purified by affinity chromatography with desorption using either $100 \mathrm{~mm}$ DECA (structures A and C) or 10 mM edrophonium (EDR) (structure B); extensively dialyzed against 1 mu MES, pH 6.5, $50 \mathrm{~mm} \mathrm{NaCl}$, and $0.01 \%(\mathrm{w} / \mathrm{v}) \mathrm{NaN}_{3}$; and prepared as described previously (19). Crystallization was achieved at $4{ }^{\circ} \mathrm{C}$ by vapor diffusion using hanging drops $(4 \mu \mathrm{l})$ and a protein/well solution ratio of $1: 1$. Well solutions were made of $1.7 \mathrm{M} \mathrm{NaKPO}_{4}, \mathrm{pH} 7.0$, and $10 \mathrm{~mm}$ $\mathrm{CaCl}_{2}$ (structure A) and $1.9 \mathrm{M} \mathrm{NaKPO}_{4}, \mathrm{pH} 7.0$, and $10 \mathrm{~mm} \mathrm{MgCl}$ (structure B), which were ice-cooled and centrifuged $\left(10,000 \times g, 4{ }^{\circ} \mathrm{C}\right)$ to remove precipitated material, or $0.95 \mathrm{M}$ sodium citrate, $\mathrm{pH} 7.0$ (structure C). Single crystals grew within 2-4 weeks to an average size of $0.2 \times 0.05 \times 0.05 \mathrm{~mm}$ whether $\mathrm{NaKPO}_{4}$ or sodium citrate was the precipitating salt.

The crystals were flash-cooled at $100 \mathrm{~K}$ using $5-20 \%$ glycerol in the well solution as cryoprotectant. Oscillation images were integrated with DENZO (20) and scaled and merged with SCALA (21) (Table I). Amplitude factors were generated with TRUNCATE (22). All three crystals belonged to the orthorhombic space group $\mathrm{P} 22_{1} 2_{1} 2_{1}$ with unit cell dimensions $a=136.5 \AA, b=173.1 \AA$, and $c=224.2 \AA$, giving $V_{m}$ values of 5.1 $\AA^{3} / \mathrm{Da}\left(76 \%\right.$ solvent) and $2.55 \AA^{3} / \mathrm{Da}(38 \%)$ for four and eight $\mathrm{mAChE}$ molecules, respectively, in the asymmetric unit (23).

Structure Determination and Refinement-Initial phases for an in- house $4.5-\AA$ resolution data set were obtained by molecular replacement using the $\mathrm{mAChE}$ molecule present in the structure of the Fas2 $\mathrm{mAChE}$ complex (Protein Data Bank 1MAH) (15) as a search model with the AMoRe program package (24). Four mAChE subunits were positioned within the asymmetric unit (correlation $=75.2 \%, R$-factor $=29.9 \%$ in the 15 to $4.5-\AA$ resolution range) and found to assemble as a dimer of the same dimers as seen in the Fas2-mAChE structure. Rigid-body refinement applied to the whole tetramer, each of the two dimers, and the individual subunits was then performed with X-PLOR (25) using synchrotron data between 8 and $3 \AA$ and gave an $R$-factor of $33 \%$. For $2 \%$ of the reflections against which the model was not refined, $R_{\text {free }}$ was $33 \%$. Several cycles of Powell conjugate-gradient minimization were then performed, and electron density maps calculated with the subsequent model were inspected with TURBO-FRODO (26).

The positions of misplaced amino and carboxyl termini and of a few side chains were adjusted, and the Pro $^{258}-$ Gly $^{264}$ portion, which was missing in the search model, was built into $2 F_{o}-F_{c}$ and $F_{o}-F_{c}$ electron density maps. In each of the subunits in the tetramer, a DECA molecule was fitted into a residual density observed within the active site (see "Results"). A glycerol molecule arising from the cryoprotection solution was positioned into a density found in the vicinity of $\mathrm{Glu}^{81}$, with the glycerol oxygen atoms hydrogen-bonded to the $\mathrm{Glu}^{452}$, $\mathrm{Glu}^{81}$, and $\mathrm{Thr}^{436}$ oxygen atoms and the carbon atoms in van der Waals interactions with the side chain of $\mathrm{Met}^{85}$. A phosphate group arising from the crystallization liquor was positioned between the Lys ${ }^{332}$ and $\mathrm{Arg}^{395}$ side chains, with its oxygen atoms bound to the $\operatorname{Trp}^{442}$ carbonyl oxygen and Lys ${ }^{332}$ nitrogen atoms. Since the non-crystallographic symmetry (NCS) was not restrained throughout these early stages of model building and refinement, subunits were then superimposed within each dimer, and different NCS constraints were applied along the molecule and used during all subsequent refinement steps. This model was refined with REFMAC (27), including all low resolution data. A conservative number of solvent molecules were manually added into the model; most of them were found to be located at nearly identical positions in the 2.5-^̊ resolution structure of TcAChE (Protein Data Bank 2ACE) (28). The conformations of some side chains were corrected using mAChE coordinates from a $2.7-\AA$ resolution structure of the Fas2.mAChE complex. ${ }^{2}$

The final structure A comprises $\mathrm{mAChE}$ residues $\mathrm{Glu}^{4}-\mathrm{Thr}^{543}$ (subunits A and D) and residues Glu ${ }^{1}-\mathrm{Cys}^{257}$ and $\mathrm{Asn}^{265}-\mathrm{Ala}^{547}$ (subunits B

\footnotetext{
${ }^{2}$ Y. Bourne, unpublished data.
} 
and C) (see Figs. 1 and 2). High temperature factors and weak electron density include mAChE residues Glu ${ }^{4}-\mathrm{Gln}^{7}$ and $\mathrm{Arg}^{493}-\mathrm{Pro}^{498}$ in all four subunits; $\mathrm{Pro}^{258}-\mathrm{Gly}^{264}$ is not visible in electron density maps of subunits B and C. The r.m.s. deviation between the two mAChE subunits of a canonical dimer is $0.06 \AA$ for tight-constraint NCS atoms, 0.16 $\AA$ for medium-constraint NCS atoms, and $0.64 \AA$ A for loose-constraint NCS atoms. Structures B and C were solved using the refined structure A (inhibitor and solvent molecules removed) as an initial model and refined to $3.1 \AA$. The r.m.s. deviation values for the backbone atoms and all atoms are 0.21 and $0.3 \AA$ between structures $\mathrm{A}$ and $\mathrm{B}, 0.13$ and 0.2 $\AA$ between structures $\mathrm{A}$ and $\mathrm{C}$, and 0.19 and $0.26 \AA$ between structures $\mathrm{B}$ and $\mathrm{C}$, respectively. The stereochemistry of all three structures was analyzed with PROCHECK (29) and WHATIF (30) (Table I). Figures were generated with the programs RIBBON (31), GRASP (32), and TURBO-FRODO (26).

\section{RESULTS AND DISCUSSION \\ Overall Description of the Structure}

The mAChE molecule, which consists of a 12-stranded central-mixed $\beta$-sheet surrounded by $14 \alpha$-helices, has the same overall conformation as found for the Fas2 $2 \mathrm{mAChE}$ complex (15): the r.m.s. deviations between the free and complexed mAChEs are $0.5 \AA$ for the backbone atoms and $0.6 \AA$ for all atoms, with the largest deviations occurring in surface loops $\left(\mathrm{Ala}^{24}-\mathrm{Gly}^{26}, \mathrm{Pro}^{108}-\mathrm{Ser}^{110}, \mathrm{Gln}^{322}-\mathrm{Leu}^{324}, \mathrm{Asp}^{372}-\mathrm{Ala}^{374}\right.$, $\mathrm{Leu}^{386}$ Pro $^{388}$, and Asp ${ }^{491}-\mathrm{Ser}^{497}$ ), in the position of domain $\mathrm{Tyr}^{341}-\mathrm{Glu}^{399}$, and in the orientation of $\mathrm{Tyr}^{337}$.

mAChE, which is devoid of the carboxyl-terminal amphipathic helix and intersubunit disulfide-linking Cys, is monomeric in dilute solution (19), but dimeric in the Fas2.mAChE crystals, where a homodimer assembles through a tightly packed four-helix bundle (15). In the mAChE crystal, two identical homodimers assemble as a tetramer in which the two four-helix bundles are aligned antiparallel (Fig. 1). The main axes of the two dimers are tilted by $\sim 35^{\circ}$ from each other to form a compact, pseudo-square planar tetramer with overall dimensions of $90 \times 90 \times 100 \AA$.

In the tetramer, a short surface loop and flanking $\alpha$-helices from subunit A of the first dimer tightly associate with the peripheral site region at the gorge entrance of the facing subunit, subunit $\mathrm{C}$ of the second dimer (Fig. 1). The inverse loopperipheral site interaction involves the loop and $\alpha$-helices of subunit $\mathrm{D}$ in the second dimer and the peripheral site region of subunit B in the first dimer. As a result, peripheral sites of the two loop-acceptor subunits, B and C, are occluded, whereas peripheral sites of the two loop-donor subunits, A and D, are accessible to the solvent, a feature unique to this structure. At the tetramer center, the carboxyl-terminal $\alpha$-helices in the four-helix bundles converge at the interface. The dimer-dimer interface, which extends over $90 \AA$ in a direction roughly perpendicular to the four-helix bundle axis, buries to a 1.6-Å probe radius, a $2500-\AA^{2}$ surface area for the two pairwise dimerdimer interfaces, an area falling in the highest range for functionally relevant crystal packing interfaces (33). Including the area buried at the four-helix bundle interface within each dimer (15), the total $\mathrm{mAChE}$ surface area buried within the tetramer encompasses $6000 \AA^{2}$.

\section{Detailed Description of the Structure (Structure A)}

At the dimer-dimer interface, mAChE loop 257-272, a short $\Omega$ loop (34) that is bridged by two Cys residues and contains the Pro-Pro-Gly-Gly-Ala-Gly-Gly sequence conserved in mammalian AChEs along with flanking $\alpha$-helices $\alpha_{6,7}^{1}$ and $\alpha_{6,7}^{2}$ (Fig. 2 ), is associated with the peripheral anionic site at the gorge entrance of the facing mAChE subunit. The helix-loop-helix domain sterically occludes access to the active center gorge (Figs. 1-3). This part of the interface involves hydrophobic and polar contacts of 12 residues from each subunit (Fig. 3). The $\mathrm{Gly}^{260}-\mathrm{Gly}^{264}$ cluster of hydrophobic residues at the loop tip
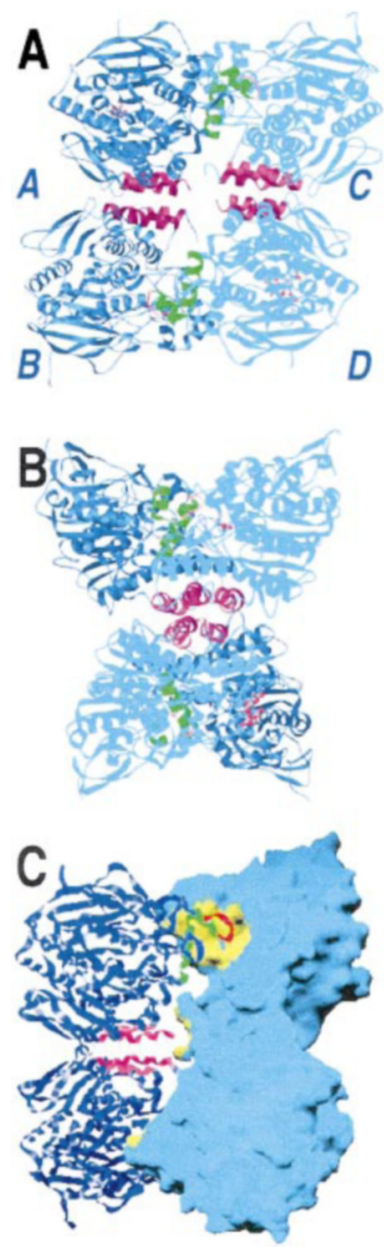

FIG. 1. Overall view of the compact, pseudo-square planar mAChE tetramer. Panel $A$, ribbon diagram of the mAChE dimer of dimers viewed perpendicular to the four-helix bundle axis. Panel $B$, the dimer of dimers viewed parallel to the four-helix bundle axis, $90^{\circ}$ from panel $A$. The italicized blue labels $A$ and $B$ refer to the subunits in the left dimer (displayed in dark blue), and labels $C$ and $D$ refer to the subunits in the right dimer (light blue) for orientation shown in panels $A$ and $C$. The four-helix bundles formed by helices $\alpha^{3}{ }_{7,8}$ and $\alpha_{10}$ from two subunits are displayed in magenta. The short $\Omega$ loop $\mathrm{Cys}^{257}-\mathrm{Cys}^{272}$ is displayed in red, and helices $\alpha_{6,7}^{1}$ and $\alpha_{6,7}^{2}$ are in green. Panel $C$, same orientation as in panel $A$ showing the molecular surface of dimer CD in blue, with the surfaces buried to a $1.6-\AA$ probe radius at the dimerdimer interface in gold. Helix $\alpha^{1}{ }_{6,7}$ in the loop region of subunit $\mathrm{C}$ is visible behind the ribbon trace of subunit A. The GlcNAc moiety and the GlcNAc- $\beta 1,4-$ GlcNAc- $\alpha 1,6$-Fuc trisaccharide moiety linked to $\mathrm{Asn}^{350}$ in subunits A and D, respectively, are displayed as gray bonds with colored spheres. Secondary structure elements are specified according to Ref. 2.

packs against peripheral site residues $\operatorname{Tyr}^{72}, \operatorname{Trp}^{286}$, and $\mathrm{Tyr}^{341}$, with predominant interactions between dipeptide Gly $^{260}-$ Gly $^{261}$ and $\operatorname{Trp}^{286}$ and between dipeptide Gly ${ }^{261}-\mathrm{Ala}^{262}$ and $\mathrm{Tyr}^{341}$. Two discrete patches of polar interactions involve the loop extremities and flanking helices with the boundary of the peripheral anionic site and appear to form three hydrogen bonds. The guanidinyl moieties of $\mathrm{Arg}^{245}$ and $\mathrm{Arg}^{253}$, located near the amino and carboxyl termini of helix $\alpha^{1}{ }_{6,7}$, respectively, form key hydrogen bonds with the side chain carboxylate and the amide backbone nitrogen atom of $\mathrm{Glu}^{292}$, and the $\mathrm{Gly}^{263}$ nitrogen forms a hydrogen bond with the $\mathrm{Tyr}^{341}$ carbonyl oxygen. The loop shows high complementarity to the peripheral anionic site, a feature arising from the flexibility imparted by the vicinal Gly residues; limited internal stabilization of conformation is achieved from the adjacent Pro residues, with $\mathrm{Pro}^{258}$ in the cis-conformation and in van der Waals contacts with $\mathrm{Ala}^{262}$. Flexibility of the loop is evident since it cannot be 


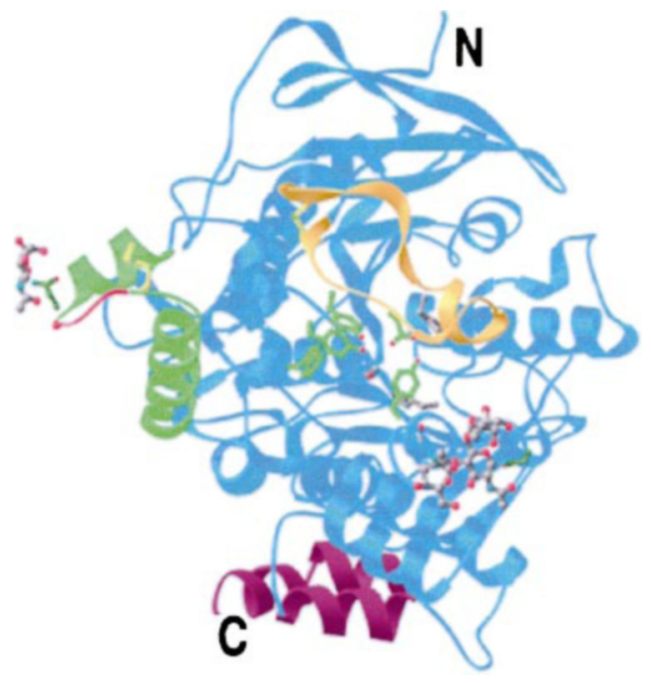

FIG. 2. Overall view of the $\mathrm{mAChE}$ molecule and localization of the short $\Omega$ loop relative to other secondary structure elements. The molecule (subunit D) is viewed down to the gorge entrance. Residues belonging to the peripheral anionic site $\left(\mathrm{Tyr}^{72}, \mathrm{Asp}^{74}, \mathrm{Tyr}^{124}\right.$, $\operatorname{Trp}^{286}$, and $\operatorname{Tyr}^{341}$ ) and residues within the active center (Trp ${ }^{86}$, Ser ${ }^{203}$, $\mathrm{Glu}^{334}$, and $\mathrm{His}^{447}$ ) are displayed as green and gray bonds with colored spheres, respectively. The short $\Omega$ loop $\mathrm{Cys}^{257}-\mathrm{Cys}^{272}$ and helices $\alpha^{1}{ }_{6,7}$ and $\alpha^{2}{ }_{6,7}$ are displayed in red and green with a yellow disulfide bridge to the left the gorge entrance. The large $\Omega$ loop $\mathrm{Cys}^{69}{ }^{6 y s}{ }^{96}$ is displayed in orange above the gorge entrance. Helices $\alpha^{3}{ }_{7,8}$ and $\alpha_{10}$, which contribute to the dimer four-helix bundle, are displayed in magenta at the bottom of the molecule. The GlcNAc moiety and the GlcNAc- $\beta 1,4-G l c N A c-\alpha 1,6$ Fuc trisaccharide moiety linked to $\mathrm{Asn}^{265}$ on the left of the molecule and to $\mathrm{Asn}^{350}$ on the right, respectively, are displayed as gray bonds with colored spheres. The labels $N$ and $C$ indicate the amino and carboxyl termini of the molecule, respectively. The carboxyl-terminal segment $\mathrm{Ala}^{544}-\mathrm{Ala}^{547}$ is not resolved in this subunit.

seen in the absence of external stabilization, as found for subunits $\mathrm{B}$ and $\mathrm{C}$ in the tetramer (Fig. 1) and in the Fas2.mAChE complex at 3.2-Å resolution (15); only the Pro doublet is seen in the Fas $2 \cdot \mathrm{mAChE}$ complex at $2.7-\AA$ 跬olution. ${ }^{2}$

The second region of the dimer-dimer interface is located centrosymmetric to the tetramer where the two four-helix bundles converge (Fig. 1). The carboxyl-terminal region, not seen in the Fas2 $\mathrm{mAChE}$ structure, is ordered sufficiently to be seen in subunits B and C, with only the carboxyl-terminal Pro ${ }^{548}$ being disordered. The two $\mathrm{Thr}^{543}$ residues at and near the carboxylterminal ends of helices $\alpha_{10}$ of subunits A and C, respectively, face each other and are separated by only $7.5 \AA$. The segment from $\mathrm{Ala}^{544}$ to $\mathrm{Ala}^{547}$ is not part of helix $\alpha_{10}$; instead, it deviates from the helix axis and exits the plane of the tetramer, perhaps because of charge repulsion between $\mathrm{Glu}^{546}$ residues of neighboring subunits in the tetramer. Accordingly, the carboxylterminal helix $\alpha_{10}$ ends at $\mathrm{Thr}^{543}$, the last residue encoded by exon 4 before the region of alternative splicing $(13,19)$.

GlcNAc moieties are observed in two of the three consensus sequences for $N$-linked glycosylation, $\mathrm{Asn}^{350}$ in subunit A, also seen in the Fas2 mAChE complex (15), and Asn ${ }^{265}$ in subunits $A$ and $D$, although the density is weaker. In addition, a GlcNAc$\beta 1,4-G l c N A c-\alpha 1,6$-Fuc trisaccharide moiety is linked to $\mathrm{Asn}^{350}$ in subunit D (Figs. 1 and 2) $(35,36)$.

\section{Comparison of the mAChE and Fas2 $m A C h E$ Structures}

The structure of mAChE at 2.9-A resolution provides greater delineation of the positions of the $\alpha$-carbon and side chains than the Fas2·mAChE complex (3.2 $\AA$ ) (15) and establishes several distinctive features of $\mathrm{mAChE}$ compared with TcAChE (Protein Data Bank 2ACE) (28). Thus, the conformations of the amino- and carboxyl-terminal segments were resolved, and the

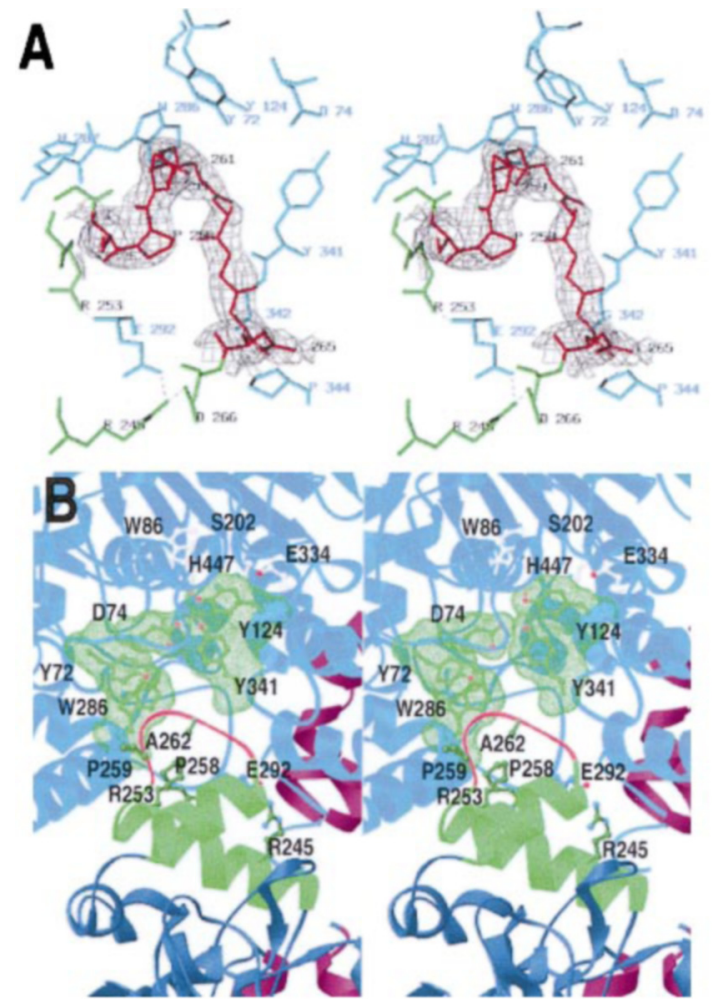

FIG. 3. Close-up view of the interaction between the loop region of subunit $A$ and the peripheral site region of subunit $C$, detailing the quality of the structure. Panel A, stereo view of the 2.90 -A resolution omit $F_{o}-F_{c}$ electron density map (contoured at $2.5 \sigma$ ) for the short $\Omega$ loop (red) and flanking helices (dark green) of subunit A and surrounding residues in the peripheral site of subunit $\mathrm{C}$. The coordinates of this region (2.5\% of the total number of atoms) were omitted, and the protein coordinates were refined by simulated annealing before the phase calculation for the map. Residues belonging to the peripheral site of subunit $\mathrm{C}$ are displayed as light green bonds, and other residues in this subunit as light blue bonds. Residues are indicated in black for subunit A and in blue for subunit C. Broken lines indicate hydrogen bonds. Panel $B$, stereo view ribbon diagram of the short $\Omega$ loop (red) and flanking helices (green) of subunit A and surrounding residues in the peripheral site of subunit $\mathrm{C}$ (same orientation as in panel $A$ ). The side chains arising from the loop region are displayed as green bonds with colored spheres. Residues belonging to the peripheral site of subunit $\mathrm{C}\left(\mathrm{Tyr}^{72}, \mathrm{Asp}^{74}, \mathrm{Tyr}^{124}, \mathrm{Trp}^{286}\right.$, and $\left.\mathrm{Tyr}^{341}\right)$ are displayed as dotted molecular surfaces and green bonds with colored spheres, and residues within the active center $\left(\operatorname{Trp}^{86}, \mathrm{Ser}^{203}, \mathrm{Glu}^{334}\right.$, and $\mathrm{His}^{447}$ ) are displayed as white bonds with colored spheres.

mAChE-specific positioning of the $\mathrm{Met}^{85}$ side chain in its stacking interaction with the indole of $\operatorname{Trp}^{86}$ was confirmed. The $\mathrm{Tyr}^{341}-\mathrm{Ser}^{399}$ rigid-body motion that was found when comparing the Fas $2 \cdot \mathrm{mAChE}$ and TcAChE structures is not apparent in mAChE; hence, movement of this domain is induced by Fas2 association (15).

The most prominent feature arising upon superimposition of the structures is the close resemblance of the two peripheral site-occluding loops, the short $\Omega$ loop of $\mathrm{mAChE}$ subunit $\mathrm{A}$ and the central loop, loop II, of Fas2 bound to $\mathrm{mAChE}$, in their positions and surface complementarity (Fig. 4). The mAChE loop and the tip of Fas2 loop II, although positioned roughly perpendicular with their respective Pro doublets not superimposable, overlap at the gorge entrance. Several side chains and backbone carbons of the mAChE loop mimic the side chains of Fas2 loop II in their interactions with residues in the peripheral anionic site. In particular, interaction of $\mathrm{Gly}^{261}$ in $\mathrm{mAChE}$ subunit A with $\operatorname{Trp}^{286}$ at the gorge entry of $\mathrm{mAChE}$ subunit C mimics the key interaction of Met ${ }^{33}$ in Fas2 with $\operatorname{Trp}^{286}$ in Fas2-associated mAChE; backbone atoms of $\mathrm{Gly}^{263}-\mathrm{Gly}^{264}$ in $\mathrm{mAChE}$ align with the side chain of $\mathrm{Lys}^{32}$ in Fas2; and Gly ${ }^{260}$ 


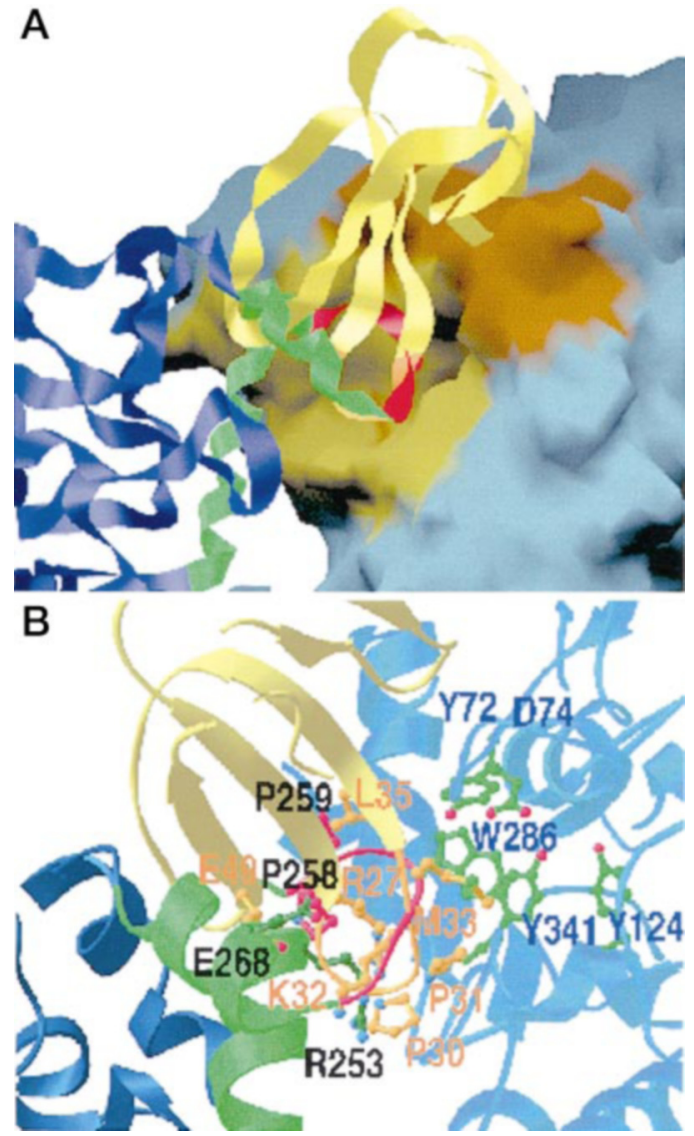

FIG. 4. Comparison of the mAChE loop-peripheral site interface with the Fas2-mAChE interface. Panel $A$, superimposition of the short $\Omega$ loop and flanking $\alpha$-helices in $\mathrm{mAChE}$ subunit A (dark blue ribbon, green helices, and red loop) with Fas2 (yellow ribbon with orange tip of loop II) bound to $\mathrm{mAChE}$ (light blue molecular surface) according to all $\mathrm{C}-\alpha$ atoms of $\mathrm{mAChE}$ subunit $\mathrm{C}$ in the tetramer and of $\mathrm{mAChE}$ in the Fas2-mAChE complex. The mAChE molecular surfaces buried at the loop-peripheral site and Fas2 $\mathrm{mAChE}$ interfaces are displayed in gold and brown, respectively. Panel $B$, close-up view of the similarity between the mAChE short $\Omega$ loop and the tip of Fas2 loop II (same color codes as in panel $A$ ). Residues belonging to the peripheral site of $\mathrm{mAChE}$ subunit $\mathrm{C}$ and the side chains arising from the loop region of subunit A are displayed as green bonds with colored spheres, and the side chains arising from Fas2 are displayed as orange bonds with colored spheres. Residues are indicated in black and blue for $\mathrm{mAChE}$ subunits A and C, respectively, and in orange for Fas2.

in $\mathrm{mAChE}$ establishes the same van der Waals contacts with Tyr $^{72}$ as does Fas2 Leu ${ }^{35}$. Several residues in helix $\alpha^{1}{ }_{6,7}$ of mAChE subunit A also adopt positions similar to residues in bound Fas2: the side chain of $\mathrm{Arg}^{253}$ in mAChE mimics, in both position and orientation, the side chain of $\mathrm{Arg}^{27}$ in Fas2, and mAChE Gly ${ }^{256}$ forms the same van der Waals contacts with $\mathrm{His}^{287}$ as Fas2 $\mathrm{Leu}^{48}$. Hence, in the tetramer, the loops that arise from two of the subunits appear to occlude substrate access to the catalytic sites of the two other subunits, similar to steric occlusion observed in the Fas2-mAChE complex. In contrast, Fas2 loop I interacts with the large $\Omega$ loop $\mathrm{Cys}^{69}-\mathrm{Cys}^{96}$ on one side of the gorge entrance, whereas mAChE helix $\alpha^{1}{ }_{6,7}$ fits into a furrow extending between the end of helix $\alpha_{6,7}^{3}$ and helix $\alpha^{2}{ }_{7,8}$, on the opposite side of the mAChE gorge entrance. Since the intersubunit and Fas2-mAChE interactions differ substantially in affinity, complexation of a disulfide-linked tetramer with fasciculin would be expected to reposition residues at the interface, a rearrangement consistent with observation of equivalent affinities of the four AChE subunits for fasciculin (37).
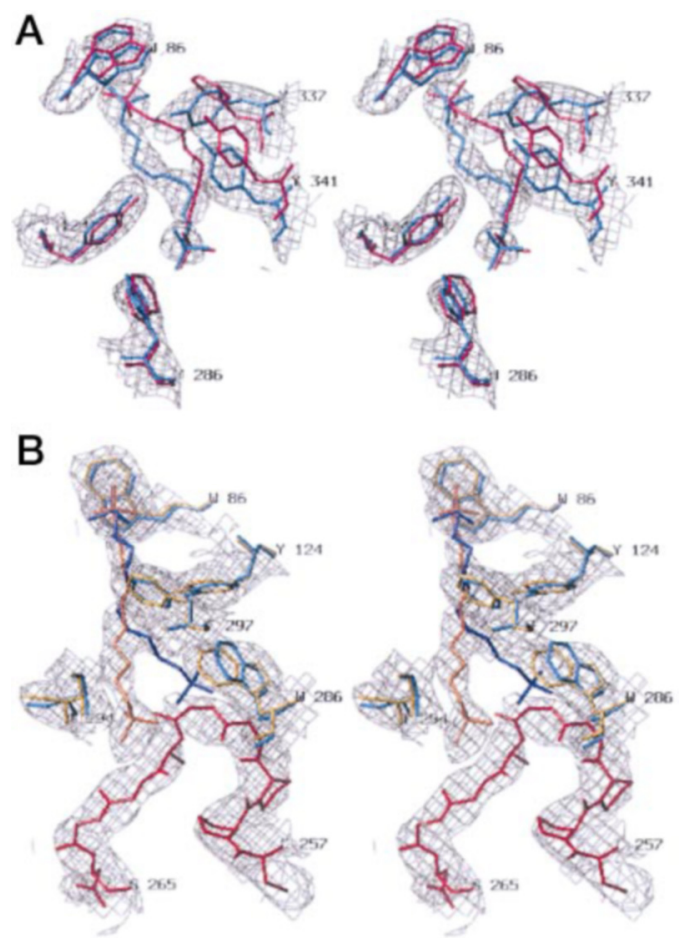

FIG. 5. Stereo views of the 2.9-A resolution electron density maps of the DECA molecules found in the active site gorges of subunits A and C. Panel A, superimposition of DECA in subunit A (blue DECA molecule and mAChE side chains) and in the DECA.TcAChE complex (red DECA molecule and TcAChE side chains) showing the omit $F_{o}-F_{c}$ map (contoured at $2.5 \sigma$ ) of DECA and surrounding residues in $\mathrm{mAChE}$ subunit $\mathrm{A}$. The coordinates of this region (2.5\% of total number of atoms) were omitted, and the protein coordinates were refined by simulated annealing before the phase calculation for the map. The peripheral anionic site of subunit A is free of an interacting loop and totally accessible to the solvent. The $90^{\circ}$ rotation of mAChE Tyr ${ }^{337}$ compared with the orientation of TcAChE Phe ${ }^{330}$ and the change in the position of $\mathrm{Tyr}^{341}$ compared with $\mathrm{TcAChE} \mathrm{Tyr}^{337}$ are evident. Panel $B$, superimposition of DECA in subunit C (orange DECA molecule, yellow $\mathrm{mAChE}$ side chains, and red loop from subunit A) and in subunit A (blue DECA molecule and $\mathrm{mAChE}$ side chains) showing the $\sigma_{\mathrm{A}}$ weighting $2 F_{o}-F_{c}$ map (contoured at $1.2 \sigma$ ) of DECA and surrounding residues in subunit $\mathrm{C}$ with the loop arising from subunit $\mathrm{A}$ $\left(180^{\circ}\right.$ from panel $A$ ). The $20^{\circ}$ tilt of $\operatorname{Trp}^{286}$ is evident. The side chain of $\mathrm{Tyr}^{341}$, which would occlude the figure, is not displayed.

\section{The mAChE Gorge and Peripheral Anionic Site}

Despite extensive dialysis (19), a DECA molecule is still present, approaching full occupancy in the active site gorges of all four mAChE subunits (Fig. 5). Superimposition of subunit A, the peripheral site of which is free of an occluding loop and totally accessible to the solvent, with TcAChE in the DECA.TcAChE complex (Protein Data Bank 1ACL) (17) shows that the proximal (N-1) and distal (N-2) quaternary ends of DECA are in van der Waals contact with the indole rings of $\operatorname{Trp}^{286}$ in the peripheral site and $\operatorname{Trp}^{86}$ in the active center and superimpose in the two structures. In mAChE, however, the 10-carbon methylene chain adopts an inverted curvature and follows the opposite wall of the gorge, a difference that involves a rotated C-5-C- 6 bond and a positioning of the C-7-C-8 bond nearly $5 \AA$ away from its position in TcAChE; hence, the C-7C-8 portion of the methylene chain winds behind the Tyr ${ }^{124}$ ring in mAChE. The conformation of DECA in $\mathrm{mAChE}$ likely results from the $90^{\circ}$ rotation of the $\mathrm{Tyr}^{337}$ phenol ring, which lies perpendicular to the gorge axis, whereas the homologous $\mathrm{Phe}^{330}$ ring in TcAChE lies parallel to the gorge axis $(17,28)$. The tyrosine hydroxyl, unique to mammalian AChEs, forces a different pathway for the methylene chain by its steric and 
polar contributions. Also, the $\mathrm{Tyr}^{341}$ ring is shifted toward the center of the gorge, $\sim 1.5 \AA$ removed from its position in TcAChE; hence, the hydroxyl moieties on $\mathrm{Tyr}^{341}$ and $\mathrm{Tyr}^{337}$ are separated by $3.8 \AA$, compared with $3 \AA$ in TcAChE. The orientation of $\mathrm{Tyr}^{337}$, also observed in the Fas $2 \cdot \mathrm{mAChE}$ complex (15), could either be intrinsic to the mouse enzyme or arise from complexation with DECA or Fas2; it is, however, identical to that of $\mathrm{Phe}^{330}$ in TcAChE in complexes with various inhibitors other than DECA $(17,28)$. Hence, fluctuations of configuration of the active center gorge of AChE permit accommodation of a large set of active center ligands.

The mAChE structure provides an initial opportunity to compare exposed and occluded peripheral sites within an asymmetric unit. However, superimposition of loop-donor subunit A with loop-acceptor subunit $\mathrm{C}$ does not reveal large differences in conformations of the two sites. r.m.s. deviations are 0.44 and $0.77 \AA$ for the main chain and all atoms, respectively; only the side chain of $\operatorname{Trp}^{286}$ at the gorge entrance of subunit $\mathrm{C}$ undergoes a $20^{\circ}$ tilt, which may arise from the steric constraint induced by the interacting loop. However, the presence of DECA in the catalytic site of non-occluded subunit A might mask structural rearrangements expected from the unliganded peripheral site. Yet in subunit $\mathrm{C}$, the bound loop partially dissociates DECA, which, although disordered, seems to adopt two discrete conformations with a hinge point near the C-4-C-5 bond. In one conformation, the proximal quaternary end of DECA interacts weakly with the indole ring of $\operatorname{Trp}^{286}$. In the second conformation, this quaternary end is displaced and flips toward the Phe $\mathrm{P}^{338}$ and $\mathrm{Ile}^{294}$ side chains, some $5 \AA$ away (Fig. $5)$. Residual inhibitor was observed in structures of native TcAChE, perhaps even with a tetramethylammonium-eluted enzyme $(14,17,28)$. In contrast, DECA is not found in the gorge of the Fas2 $\mathrm{mAChE}$ complex (15), consistent with the inhibitor molecule being displaced by bound Fas2 and eliminated during dialysis of the complex prior to crystallization (19).

\section{Other Crystal Forms of mAChE}

Structures B and C are essentially identical to structure A. However, structure B contains residual EDR instead of DECA in the active site of all four subunits (data not shown). Comparison of $\mathrm{mAChE}$ in this structure with TcAChE in the EDR.TcAChE complex (Protein Data Bank 1ACK) (17) shows similar overall positioning of the EDR molecule, located between $\mathrm{His}^{447}, \mathrm{Ser}^{203}, \mathrm{Tyr}^{337}$, and Trp86 in mAChE; however, a $30^{\circ}$ tilt of the EDR ring is observed, which may arise from accommodation to the $\mathrm{Tyr}^{337}$ orientation found in $\mathrm{mAChE}$. There is no difference between subunits A and C, indicating that the occluding loop, which is too short to sterically destabilize the associated EDR, does not perturb it allosterically. Also, bound Fas2 does not dissociate residual EDR from the active site of the complexed enzyme. ${ }^{2}$

Structure C originates from a crystal grown in conditions different from those used for the structure A crystal and contains no bound phosphate. In subunit A, a sialic acid moiety, Sia- $\alpha 2,6-$ Gal, was fitted into an unaccounted density proximal to $\mathrm{His}^{287}$ and appears to be terminal to the oligosaccharide chain GlcNAc- $\beta 1,4-$ GlcNAc- $\beta 1,4-\mathrm{Man}-\alpha 1,3-\mathrm{Man}$, linked to $\mathrm{Asn}^{350}$ (data not shown) (36); the junction between the last Man and Gal moieties was not resolved, but $\mathrm{Asn}^{350}$ is located $25 \AA$ away from $\mathrm{His}^{287}$, a value consistent with the mean distance between the two ends of an $N$-linked carbohydrate chain. A similar carbohydrate chain may be linked to $\mathrm{Asn}^{350}$ in subunit $\mathrm{D}$, although a weaker density is observed. $\mathrm{mAChE}$ is composed of two species of roughly equal populations proposed to differ in their carbohydrate composition or some other posttranslational modification (19). Combined gel-filtration, poly- acrylamide gel electrophoresis, and isoelectric focusing experiments showed that the population of a higher mass is of a lower $\mathrm{pI},{ }^{3}$ an observation consistent with sialic acid in only two subunits in the mammalian tetramer (35).

\section{Significance of the Structure}

Quaternary Structure of $m A C h E$-A square planar model for association of catalytic and structural subunits was recently proposed based on sequence alignments, computational predictions, and mutagenesis and biochemical data (38). The tetrameric structure of $\mathrm{mAChE}$ (Fig. 1) largely agrees with this model. Recombinant $\mathrm{mAChE}$, however, is truncated after residue 548; hence, it lacks the carboxyl-terminal sequences encoded by the alternatively spliced exons and is expressed as a monomer (19), a feature that poses the question of whether physiological forms of the enzyme would form a similar tetramer. In mouse, the alternatively spliced sequences are: $(a)$ a 30 -amino acid polar sequence encoded by the retained intron, (b) a glycophospholipid signal sequence that is cleaved at selected positions upon addition of the glycophospholipid, or (c) a 40-amino acid peptide containing an amphipathic helix and a free cysteine. Only the last splicing option allows for tetrameric assembly in situ $(4,39)$; assembly may be facilitated by the amphipathic helix- and polyproline-containing peptides (5). Nevertheless, truncated $\mathrm{mAChE}$ associates as dimers in concentrated solution and as dimers and tetramers in the crystals. Upon gel filtration at protein concentrations used for crystallization and low ionic strength $(10-12 \mathrm{mg} / \mathrm{ml} ; \mu=50 \mathrm{~mm})$, $\mathrm{mAChE}$ elutes as a dimer, whereas at concentrations $<100$ $\mu \mathrm{g} / \mathrm{ml}$, it elutes as a monomer; tetramers were not detected under these conditions or at high ionic strengths $(\mu=3 \mathrm{M})$ approaching the crystallization conditions. ${ }^{3}$ Since protein concentrations exceeding those for dimer formation are apparently required to detect tetramers, it seems unlikely that occlusion of internal sites as seen in the structure would influence kinetic studies, typically conducted at low enzyme concentrations.

Deviation of the mAChE carboxyl termini out from the tetramer plane (Fig. 1) suggests that the twisted square planar structure could accommodate, on each side and with minimal perturbation, alternatively spliced sequences serving either as attachment sites for structural subunits or as membrane-anchoring domains. Since both amphiphilic and non-amphiphilic tetramers appear to form from a single splice variant (40), discrete tetrameric species are likely where the amphipathic carboxyl-terminal sequences are either buried or exposed. Related tetrameric arrangements of catalytic subunits were recently observed in two 4.5 - $\AA$ resolution crystal structures determined from two distinct crystal forms of trypsin-released tetrameric AChE from Electrophorus electricus: (a) a loose pseudo-square planar arrangement with free space in the center where the carboxyl-terminal sequences might be buried and (b) a compact square non-planar arrangement in which a folding of the tetramer along the dimer-dimer interface axis exposes the four sequences on the same side. ${ }^{2}$ Comparison of these two arrangements with that of $\mathrm{mAChE}$ indicates significant flexibility of the tetramer about the four-helix bundle axis and along the dimer-dimer interface axis. Hence, more than a single tetrameric arrangement may exist to accommodate the discrete carboxyl-terminal sequences.

Conformational Mobility of $m A C h E-\Omega$ loops are often important for protein stability and function and are so positioned for molecular recognition; $\Omega$ loop lids, which are flexible until substrate or inhibitor is bound, are thought to play a role in enzymatic catalysis (34). Conformational gating provides a

\footnotetext{
${ }^{3}$ P. Marchot, unpublished data.
} 
mechanism to recruit substrates to the active site, to exclude solvent, to sequester reactive intermediates, or to enhance substrate specificity. Conformational mobility of loop Cys ${ }^{69}-\mathrm{Cys}^{96}$, the large $\Omega$ loop that is structurally homologous to the lid that sequesters the substrate in certain neutral lipases, which also show the $\alpha / \beta$-hydrolase fold $(1,2)$, has been proposed in gating accessibility of small molecules to the active center and in allosteric modulation of AChE catalysis (41-43). In the lipases, lid opening uncovering the catalytic site is a key feature of interfacial activation; however, the lid domain may be formed by one or more helices or surface loops that differ not only in length and sequence, but also in location relative to the $\alpha / \beta$ hydrolase core and the active site $(44-49)$. In several $\alpha / \beta$ hydrolase proteins, the domain located between strands $\beta_{6}$ and $\beta_{7}$ is quite independent of the $\alpha / \beta$-hydrolase core and can accommodate large insertions such as a regulatory module (50), a putative helical lid (45), or a capping domain for the active site (51), without perturbing the core structure. The flexible short $\Omega$ loop $\mathrm{Cys}^{257}-\mathrm{Cys}^{272}$, which is also located between strands $\beta_{6}$ and $\beta_{7}$ of $\mathrm{mAChE}$ and protrudes to the surface of the molecule not far from the gorge entrance (Fig. 2), and helix $\alpha^{1}{ }_{6,7}$, where several residues interact with the facing subunit in the tetramer (Figs. 1 and 3), are virtually conserved in the entire $\alpha / \beta$-hydrolase family ( $c f$. alignment in Refs. 2,50 , and 52-55). Yet a conformational rearrangement of helix $\alpha^{1}{ }_{6,7}$ or $\alpha^{2}{ }_{6,7}$ (or both) would be required for the mAChE helix-loop-helix region to fold back and interact with the peripheral anionic site of the same mAChE subunit. Partial melting of $\alpha$-helices into $\beta$-sheets participates in structural reorganization of the human pancreatic lipase lid (49). Unwinding of a helical turn, refolding of a flexible connection, and cis,trans-isomerization of a Pro residue acting as a hinge point accompany positional shift of the flap in Candida rugosa lipase (47). The mobile surface loop of cytochrome $c$ peroxidase mutant W191G contains the Pro ${ }^{190}$ Gly-Gly-Ala-Ala-Asn-Asn ${ }^{196}$ sequence, which shows striking similarity to the mAChE short $\Omega$ loop, and is followed by an $\alpha$-helix starting at $\mathrm{Asn}^{196}$, similar to mAChE helix $\alpha^{2}{ }_{6,7}$. Movement of the peroxidase loop involves a double-hinged rotation about Pro ${ }^{190}$ and $\mathrm{Asn}^{195}$ with a cis,trans-isomerization of Pro ${ }^{190}$ and an interchange in the positions of the $\operatorname{Asn}^{195}$ side and main chain atoms $(56,57)$. Hence, the sequence of the short $\Omega$ loop and the cis-conformation of $\mathrm{Pro}^{258}$ at its base should confer conformational flexibility to the helix-loop-helix domain of mAChE.

Heterologous Associations on AChE Surfaces-Certain brain regions contain large amounts of $\mathrm{AChE}$, but are devoid of acetylcholine and its biosynthesis capacity. This disparity in localization and the appreciable secretion of AChE into extracellular space suggest that AChE may have a signaling function independent of substrate catalysis (58-60). Non-catalytic properties of AChE may also play a role in neuropathology. Colocalization of AChE and amyloid $\beta$-peptide deposits in the brain of Alzheimer's disease patients indicates a presence, if not an active role, in amyloid plaque formation (8-11). AChE was demonstrated to accelerate the assembly of amyloid $\beta$-peptides into Alzheimer's fibrils, with a possible involvement of the peripheral anionic site (12, 61-63).

The solution structure of amyloid $\beta$-peptide-(1-40) shows a helix-loop-helix motif with a disordered central loop (64). Superimposition of this structure with that of the helix-loop-helix domain of $\mathrm{mAChE}$ (subunit A) brings several side chains in the $\beta$-peptide and mAChE in the same position (Fig. 6). In particular, $\mathrm{Lys}^{16}, \mathrm{Ala}^{21}$, and $\mathrm{Val}^{24}$ in the $\beta$-peptide superimpose with $\mathrm{Arg}^{247}, \mathrm{Ala}^{252}$, and $\mathrm{Val}^{255}$ in $\mathrm{mAChE}$, respectively. Moreover, the side chains of $\mathrm{His}^{14}$ in the $\beta$-peptide and $\mathrm{Arg}^{245}$ in $\mathrm{mAChE}$ align, a position suitable for hydrogen bonding with $\mathrm{Glu}^{292}$ in mAChE ( $f$. subunit C). Finally, the side chains of $\mathrm{Glu}^{22}$ in the
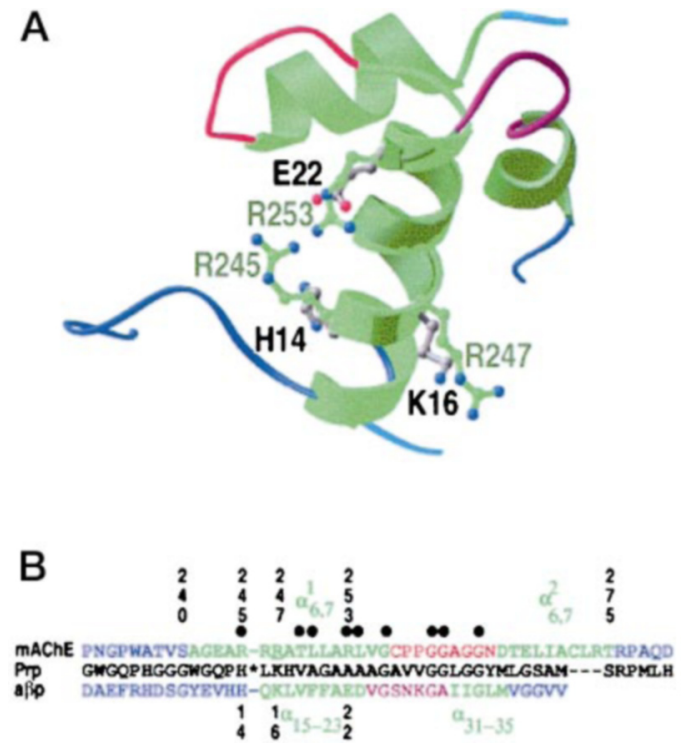

FIG. 6. Comparison of the mAChE helix-loop-helix domain with the human amyloid $\beta$-peptide and the rat prion protein. Panel A, superimposition of the structures of the $\mathrm{mAChE}$ domain (residues 232-280) and the amyloid $\beta$-peptide-(1-40) (1 conformer out of 20) (64) according to the $\mathrm{C}-\alpha$ atoms of $\mathrm{mAChE}$ helix $\alpha^{1}{ }_{67}$ and $\beta$-peptide helix $\alpha_{15-23}$, with blue coils, green $\alpha$-helices, and red (mAChE) and magenta ( $\beta$-peptide) loops. The side chains of selected residues in the $\mathrm{mAChE}$ domain and in the $\beta$-peptide are displayed as green and gray bonds with colored spheres, respectively. Panel $B$, comparison of the $\mathrm{mAChE}$ domain sequence with alignment of the amyloid $\beta$-peptide sequence $(A \beta p)$ and the prion protein sequence (Prp; sequence 85-146, with the asterisk representing a 23-residue insertion) (64) (same color codes as in panel $A$ ). Black dots above the $\mathrm{mAChE}$ sequence indicate the $\mathrm{mAChE}$ residues that bury $10 \%$ or more of their side chain surface area at the loop-peripheral site interface. Numbering above and below the $\mathrm{mAChE}$ and amyloid $\beta$-peptide sequences refers to residues whose side chains are displayed in panel $A$.

$\beta$-peptide and $\mathrm{Arg}^{253}$ in $\mathrm{mAChE}$ also align (as does the side chain of $\mathrm{Arg}^{27}$ in bound Fas2), a substitution that likely disrupts polar interactions, but not van der Waals contacts, with $\mathrm{Pro}^{290}$ and $\mathrm{His}^{287}$ in the peripheral site of $\mathrm{mAChE}$. In solution, the high mobility of the two loops may bring dipeptides $\mathrm{Val}^{24}$ $\mathrm{Gly}^{25}$ and $\mathrm{Gly}^{29}-\mathrm{Ala}^{30}$ in the $\beta$-peptide in the same positions as $\mathrm{Val}^{255}$ Gly $^{256}$ and Gly ${ }^{260}$ Gly $^{261}$ in mAChE. Hence, the amyloid $\beta$-peptide and the $\mathrm{mAChE}$ helix-loop-helix domain may interact in a similar manner with the AChE peripheral anionic site, which could serve as a nucleation site to promote aggregation.

Conformational plasticity of the amyloid $\beta$-peptides permits not only variable positioning of $\alpha$-helices, but also local $\beta$-strand structures (64-66). In the amyloid $\beta$-peptides, as in the prion proteins, an $\alpha$-helix to $\beta$-sheet conversion was proposed to accompany aggregation (67). Sequence analysis revealed similarity of the amyloid protein region $\mathrm{Gln}^{15}-\mathrm{Gly}^{37}$ to the prion protein region $\mathrm{Met}^{120}-\mathrm{Gly}^{142}$ (64), a region suggested to undergo $\alpha$-helix to $\beta$-sheet transition in the pathogenic states $(68-70)$. In addition to its structural similarity to the amyloid $\beta$-peptide, the mAChE helix-loop-helix domain with its glycine cluster shows intriguing sequence similarity to the $\mathrm{Met}^{120}-$ Gly $^{142}$ region of the prion proteins (Fig. 6). This feature also makes rearrangement of the $\mathrm{mAChE}$ domain an attractive consideration.

In summary, the crystal structure of mAChE shows a tetrameric assembly of subunits; points to flexibility within the active center gorge; and reveals the peripheral anionic site, at the rim of the gorge, to be the site of association of surface loops not only from inhibitory peptides, but also from adjacent subunits. Hence, this may also be a site for heterologous protein association with AChE. 
Acknowledgments-We thank Joan Kanter (University of California at San Diego) for purification of the recombinant enzyme; Philippe Cantau and Didier Nurizzo (CNRS) for help in in-house and synchrotron data collection, respectively; and Christian Cambillau (CNRS) for interest and support. Expert assistance from Victor Lamzin (EMBLDeutsches Elektronen-Synchrotron) and Javier Pérez (Laboratoire pour l'Utilisation du Rayonnement Electromagnétique) is much appreciated.

\section{REFERENCES}

1. Ollis, D. L., Cheah, E., Cygler, M., Dijkstra, B., Frolow, F., Franken, S. M., Harel, M., Remington, J. S., Silman, I., Schrag, J. D., Sussman, J. L., Verschueren, K. H. G., and Goldman, A. (1992) Protein Eng. 5, 197-211

2. Cygler, M., Schrag, J., Sussman, J. L., Harel, M., Silman, I., Gentry, M. K., and Doctor, B. P. (1993) Protein Sci. 2, 366-382

3. Massoulié, J., Pezzementi, L., Bon, S., Krejci, E., and Valette, F. M. (1993) Prog. Neurobiol. (Oxf.) 41, 31-91

4. Taylor, P., and Radic', Z. (1994) Annu. Rev. Pharmacol. Toxicol. 34, 281-320

5. Bon, S., Coussen, F., and Massoulié, J. (1997) J. Biol. Chem. 272, 3016-3021

6. Atack, J. R., Perry, E. K., Bonham, J. R., Perry, R. H., Tomlinson, B. E., Blessed, G., and Fairbairn, A. (1983) Neurosci. Lett. 40, 199-204

7. Schegg, K. M., Harrington, L. S., Nielsen, S., Zweig, R. M., and Peacock, J. H. (1992) Neurobiol. Aging 13, 697-704

8. Geula, C., and Mesulam, M. M. (1994) in Alzheimer Disease (Terry, R. D., Katzman, R., and Bick, K. L., eds) pp. 263-291, Raven Press, New York

9. Carson, K. A., Geula, C., and Mesulam, M. M. (1991) Brain Res. 540, $2204-2208$

10. Moran, M. A., Mufson, E. J., and Gomez-Ramos, P. (1993) Acta Neuropathol. 85, 362-369

11. Ulrich, J., Meier-Ruge, W., Probst, A., Meier, E., and Ipsen, S. (1990) Acta Neuropathol. 80, 624-628

12. Alvarez, A., Alarcon, R., Opazo, C., Campos, E. O., Munoz, F. J., Calderon, F. H., Dajas, F., Gentry, M. K., Doctor, B. P., De Mello, F. G., and Inestrosa, N. (1998) J. Neurosci. 18, 3213-3223

13. Rachinsky, T. L., Camp, S., Li, Y., Ekström, J., Newton, M., and Taylor, P. (1990) Neuron 5, 317-327

14. Sussman, J. L., Harel, M., Frolow, F., Oefner, C., Goldman, A., Toker, L., and Silman, I. (1991) Science 253, 872-879

15. Bourne, Y., Taylor, P., and Marchot, P. (1995) Cell 83, 503-512

16. Harel, M., Kleywegt, G. J., Ravelli, R. B. G., Silman, I., and Sussman, J. L. (1995) Structure 3, 1355-1366

17. Harel, M., Schalk, I., Ehret-Sabatier, L., Bouet, F., Goeldner, M., Hirth, C., Axelsen, P. H., Silman, I., and Sussman, J. L. (1993) Proc. Natl. Acad. Sci. U. S. A. 90, 9031-9035

18. Axelsen, P. H., Harel, M., Silman, I., and Sussman, J. L. (1994) Protein Sci. 3, 188-197

19. Marchot, P., Ravelli, R. B. G., Raves, M. L., Bourne, Y., Vellom, D. C., Kanter, J., Camp, S., Sussman, J. L., and Taylor, P. (1996) Protein Sci. 5, 672-679

20. Otwinowski, Z. (1993) in Proceedings of the CCP4 Study Weekend on Data Collection \& Processing (Sawyer, L., Issacs, N., and Burley, S., eds) pp. 56-62, Science and Engineering Research Council/Daresbury Laboratory, Warrington, England

21. Evans, P. R. (1993) in Proceedings of the CCP4 Study Weekend on Data Collection \& Processing (Sawyer, L., Issacs, N., and Burley, S., eds) pp. 114-122, Science and Engineering Research Council/Daresbury Laboratory, Warrington, England

22. CCP4 Collaborative Computational Project No. 4 (1994) Acta Crystallogr. Sect. D 50, 760-763

23. Matthews, B. W. (1968) J. Mol. Biol. 33, 491-497

24. Navaza, J. (1994) Acta Crystallogr. Sect. A 50, 157-163

25. Brünger, A. T., Kuriyan, J., and Karplus, M. (1987) Science 235, 1118-1135

26. Roussel, A., and Cambillau, C. (1989) in Silicon Graphics Geometry Partners Directory (Silicon Graphics Committee, eds) pp. 77-78, Silicon Graphics, Mountain View, CA

27. Murshudov, G. N., Vagin, A. A., and Dodson, E. J. (1997) Acta Crystallogr Sect. $D$ 53, 240-255

28. Raves, M. L., Harel, M., Pang, Y.-P., Silman, I., Kozikowski, A. P., and Sussman, J. L. (1997) Nat. Struct. Biol. 4, 57-63

29. Laskowski, R. A., MacArthur, M. W., Moss, D. S., and Thornton, J. M. (1993) J. Appl. Crystallogr. 26, 283-291

30. Hooft, R. W. W., Vriend, G., Sander, C., and Abola, E. E. (1996) Nature 381, 272
31. Carson, M. (1991) J. Appl. Crystallogr. 24, 958-961

32. Nicholls, A. (1992) GRAPS: Graphical Representation and Analysis of Surface Properties, Columbia University, New York

33. Janin, J. (1997) Nat. Struct. Biol. 4, 973-974

34. Fetrow, J. S. (1995) FASEB J. 9, 708-717

35. Saxena, A., Ashani, Y., Raveh, L., Stevenson, D., Patel, T., and Doctor, B. P. (1998) Mol. Pharmacol. 53, 112-122

36. Kornfeld, R., and Kornfeld, S. (1985) Annu. Rev. Biochem. 54, 631-664

37. Marchot, P., Khélif, A., Ji, Y.-H., Mansuelle, P., and Bougis, P. E. (1993) J. Biol. Chem. 268, 12458-12467

38. Giles, K. (1997) Protein Eng. 10, 677-685

39. Li, Y., Camp, S., and Taylor, P. (1993) J. Biol. Chem. 268, 5790-5797

40. Duval, N., Massoulié, J., and Bon, S. (1992) J. Cell Biol. 118, 641-653

41. Gilson, M. K., Straatsma, T. P., McCammon, J. A., Ripoll, D. R., Faerman, C. H., Axelsen, P. H., Silman, I., and Sussman, J. L. (1994) Science 263, $1276-1278$

42. Faerman, C., Rippol, D., Bon, S., Le Feuvre, Y., Morel, N., Massoulié, J., Sussman, J. L., and Silman, I. (1996) FEBS Lett. 386, 65-71

43. Velan, B., Barak, D., Ariel, N., Leitner, M., Bino, T., Ordentlich, A., and Shafferman, A. (1996) FEBS Lett. 395, 22-28

44. Brzozowski, A. M., Derewenda, U., Derewenda, S. Z., Dodson, G. G., Lawson, D. M., Turkenburg, J. P., Bjorkling, F., Huge-Jensen, B., Patkar, S. A., and Thim, L. (1991) Nature 351, 491-494

45. Noble, M. E. M., Cleasby, A., Johnson, L. N., Egmond, M. R., and Frenken, L. G. J. (1993) FEBS Lett. 331, 123-128

46. Schrag, J. D., and Cygler, M. (1993) J. Mol. Biol. 230, 575-591

47. Grochulski, P., Li, Y., Schrag, J. D., and Cygler, M. (1994) Protein Sci. 3, 82-91

48. Grochulski, P., Li, Y., Schrag, J. D., Bouthillier, F., Smith, P., Harrison, D., Rubin, B., and Cygler, M. (1993) J. Biol. Chem. 268, 12843-12847

49. van Tilbeurgh, H., Egloff, M. P., Martinez, C., Rugani, N., Verger, R., and Cambillau, C. (1993) Nature 362, 814-820

50. Contreras, J. A., Karlsson, M., Østerlund, T., Laurell, H., Svensson, A., and Holm, C. (1996) J. Biol. Chem. 271, 31426-31430

51. Franken, S. M., Rozeboom, H. J., Kalk, K. H., and Dijkstra, B. W. (1991) EMBO J. 10, 1297-1302

52. Cousin, X., Bon, S., Duval, N., Massoulié, J., and Bon, C. (1996) J. Biol. Chem. 271, 15099-15108

53. Darboux, I., Barthalay, Y., Piovant, M., and Hipeau-Jacquotte, R. (1996) EMBO J. 15, 4835-4843

54. Ichtchenko, K., Nguyen, T., and Südhof, T. C. (1996) J. Biol. Chem. 271, $2676-2682$

55. Simon, S., and Massoulié, J. (1997) J. Biol. Chem. 272, 33045-33055

56. Fitzgerald, M. M., Churchill, M. J., McRee, D. E., and Goodin, D. B. (1994) Biochemistry 33, 3807-3818

57. Fitzgerald, M. M., Musah, R. A., McRee, D. E., and Goodin, D. B. (1996) Nat. Struct. Biol. 3, 626-631

58. Greenfield, S. (1995) in Enzymes of the Cholinesterase Family (Quinn, D. M., Balasubramanian, A. S., Doctor, B. P., and Taylor, P., eds) pp. 415-421, Plenum Publishing Corp., New York

59. Layer, P. G., and Willbold, E. (1995) Prog. Histochem. Cytochem. 29, 1-99

60. Small, D. H., Michaelson, S., and Sberna, G. (1996) Neurochem. Int. 28, $453-483$

61. Alvarez, A., Opazo, C., Alarcon, R., Garrido, J., and Inestrosa, N. (1997) J. Mol. Biol. 272, 348-361

62. Inestrosa, N. C., Alvarez, A., Pérez, C. A., Moreno, R. D., Vicente, M., Linker, C., Casanueva, O. I., Soto, C., and Garrido, J. (1996) Neuron 16, 881-891

63. Reyes, A. E., Pérez, D. R., Alvarez, A., Garrido, J., Gentry, M. K., Doctor, B. P., and Inestrosa, N. (1997) Biochem. Biophys. Res. Commun. 232, 652-655

64. Sticht, H., Bayer, P., Willbold, D., Dames, S., Hilbich, C., Beyreuther, K., Frank, R. W., and Rösch, P. (1995) Eur. J. Biochem. 233, 293-298

65. Talafous, J., Marcinowski, K. J., Klopman, G., and Zagorski, M. G. (1994) Biochemistry 33, 7788-7796

66. Soto, C., Brañes, M. C., Alvarez, J., and Inestrosa, N. C. (1994) J. Neurochem. 63, 1191-1198

67. Soto, C., Castaño, E. M., Frangione, B., and Inestrosa, N. (1995) J. Biol. Chem. 270, 3063-3067

68. Beyreuther, K., and Masters, C. L. (1994) Nature 370, 419-420

69. Kocisko, D. A., Come, J. H., Priola, S. A., Chesebro, B., Raymond, G. J., Lansbury, P. T., and Caughey, B. (1994) Nature 370, 471-474

70. Nguyen, J., Baldwin, M. A., Cohen, F. E., and Prusiner, S. B. (1995) Biochemistry 34, 4186-4192 